\title{
AR CONDICIONADO EM AMBIENTES ASSÉPTICOS
}

\author{
Marilda Aparecida Pierini*
}

\section{1 - INTRODUÇÃO}

A importância de um sistema de ar condicionado para hospitais é assunto que requer estudo mais pormenorizado, pois o que já foi feito até agora em termos de instalações, foi o produto de observação superficial dos conceitos e métodos utilizados em países mais desenvolvidos e muitas vezes aplicados erroneamente.

E básico que um sistema de ar condicionado para Centro Cirúrgico deva contribuir para a manutenção das condições assépticas do ambiente. Entretanto, muitas vezes os cirurgiōes trabalham em condições precárias de assepsia, com sistema de ar condicionado inadequado.

Desde 1971, o assunto em epígrafe vem de encontro aos interesses do Hospital das Clínicas da U.S.P., quando se iniciou o Grupo de Controle de Infeç̧ões Hospitalares (GTCIH) que se preocupa em prevenir e controlar as infecções ou os focos que possam diminuir as condições assépticas exigidas em algumas áreas do Hospital, como Centro Cirúrgico e Unidades de Tratamento Intensivo.

\section{2 - SISTEMA DE AR CONDICIONADO USADO EM NOSSOS HOS- PITAIS}

Para facilitar nossa exposição, focalizaremos os sistemas de ar condicionado mais comumente usado em nossos hospitais.

\section{CARACTERISTICAS}

2.1.1. Filtro normal de espuma de poliuretano;

2.1.2. Filtragem deficiente;

* Supervisora do C.C. do Hospital das Clínicas da F.M.U.S.P. 


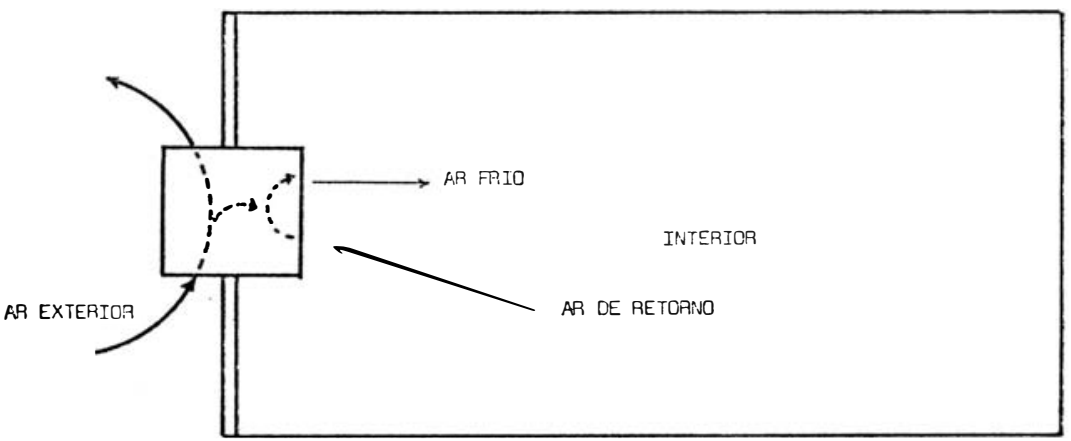

2.1.3. Funciona com ar de retorno (recirculação de ar) com pouca renovação de ar;

2.1.4. Não tem possibilidades de adaptação de filtros especiais (filtros absolutos de papel, com 99\% de deficiência);

2.1.5. Não tem possibilidades de controle da umidade relativa;

2.1.6. Não é adaptado para verão (resfriamento) ou para verão e inverno (resfriamento e aquecimento), podendo o aquecimento ser feito por aquecedor elétrico ou por reversão do ciclo.

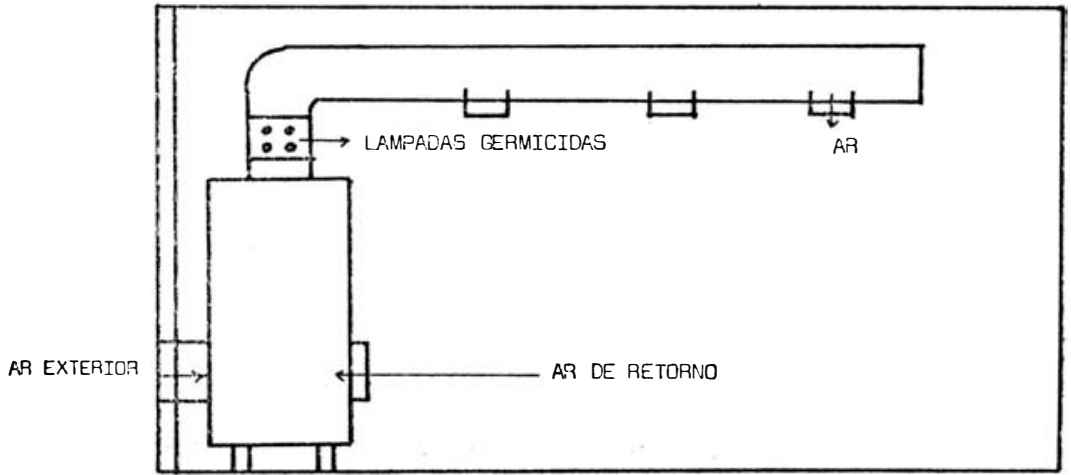




\section{CARACTERISTICAS}

2.2.1. Filtro normal de tela metálica ou espuma de poliuretano, com possibilidade de se adaptar em complementação filtros especiais (filtros absolutos de papel, com $99 \%$ de eficiência);

2.2.2. uma parte do ar retorna ao condicionador e outra parte é tomada de fora;

2.2.3. há possibilidade de controle da umidade relativa com colocação de umidificador (no caso de sala de operação por exemplo);

2.2.4. há possibilidade de adaptação de lâmpadas germicidas;

2.2.5. pode funcionar para resfriamento apenas ou resfriamento e aquecimento (este, na maioria dos casos, por aquecedores elétricos).

2.3. CONDICIONADOR SELF - CONTAINED SEM AR DE RETORNO

(SEM RECIRCULAÇ,ÃO)

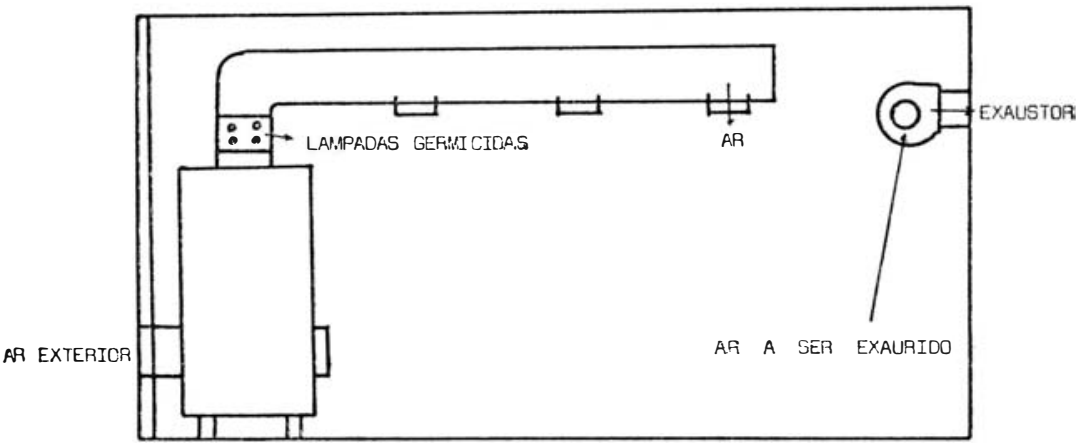

\section{CARACTERISTICAS}

2.3.1. Filtro normal de tela metálica ou espuma de poliuretano com possibilidade de adaptar em complementação filtros especiais (filtros absolutos de papel, com $99 \%$ de eficiência);

2.3.2. todo ar insuflado é exaurido por um sistema de exaustão, sendo eliminado para o exterior; não há recirculação de ar sendo todo o ar, tomado por fora;

2.3.3. há possibilidade de controle da umidade relativa com colocação de umidificador (no caso de sala de operação por exemplo) ;

2.3.4. há possibilidade de adaptação de lâmpadas germicidas; 
2.3.5. pode funcionar para refriamento apenas ou resfriamento e aquecimento (este, na maioria dos casos, por aquecedores elétricos).

\section{3 - SISTEMA DE CIRCULAÇÃO DO AR DENTRO DAS SALAS CIRÚRGICAS - TRATAMENTO BÁSICO}

Bourdillon et Coelbrock num estudo de contagem dos germes da flora bacteriana do ar dentro de um hospital, obtiveram os seguintes resultados: 300 bactérias $/ \mathrm{m}^{3}$ numa sala de operação, 70.000 bactérias $/ \mathrm{m}^{3}$ numa enfermaria e 5.245 bactérias $/ \mathrm{m}^{3}$ na atmosfera exterior do mesmo hospital. Outro estudo feito por Greene et Col. em dois outros hospitais mostrou a prevalência em porcentagem dos tipos de germes encontrados no ar: $61,8 \%$ de germes Grampositivos, $14 \%$ de Gram-negativos e $24,2 \%$ de outros tipos.

Outro estudo do GTCIH do Hospital das Clínicas em 1971 mostrou a existência de incontáveis Stafilococos Aureus na porta de entrada do Centro Cirúrgico que fica próxima a um ambulatório de cirurgia.

Esses estudos podem sugerir porque a infecção hospitalar é uma preocupação constante apesar do aparecimento dos antibióticos. Por um lado as bactérias que vão se tornando resistentes aos antibióticos e por outro lado a infecção cruzada que se tem apresentado em primeiro plano. Portanto, uma medicina atual mais audaciosa é uma explicação, mas, não é uma justificação.

Como ilustração, farei uma rápida descrição e algumas recomendações do processamento do ar em salas cirúrgicas, válidas para todo o hospital.

\subsection{Sistema com recirculação total}

São os condicionadores de janela, apropriados somente para escritórios, salas de reuniões, ambientes domésticos etc. e totalmente obsoletos para salas cirúrgicas. Este tipo de sistema não permite adaptação de filtros especiais, pois o ventilador não tem capacidade para impulsionar o ar através da sala.

\subsection{Sistema com Recirculação Parcial}

Faz-se a recirculação do ar, passando-se obrigatoriamente por um filtro absoluto (HEPA) 1 que é o mais indicado para áreas onde se requer alto grau de limpeza e esterilização.

1. High Efficiency Particulate Air Filters - desenvolvido pela Comissão de Energia Atômica Americana para filtrar poeira radioativa. Sua eficiência é superior a $99,7 \%$ com particulas de 0,3 micras. 


\subsection{Sistema sem recirculação}

Este sistema não permite a recirculação que é a maior fonte geradora de partículas contaminantes $/ \mathrm{m}^{3}$ de ar. Pode ser usado um filtro de alta eficiência tipo HEPA ou outros de menos eficiência tipo FARR, AMERICAN AIR FILTER etc.

E importante lembrarmos que num sistema com recirculação total ou parcial do ar instalado num Centro Cirúrgico onde haja centro séptico, a cada abertura da porta da sala de operação estamos trazendo para o ambiente asséptico o ar do corredor ou de outra sala cirúrgica que eventualmente esteja em frente.

Num sistema sem recirculação "self contained", é discutível a altura da instalação do exaustor, considerando-se que as partículas tendem a depositar-se nas partes mais baixas do ambiente.

Neste sistema faz-se necessário lembrar que o exaustor deve estar distanciado da porta de entrada do ar de renovação para que o ar volte ao aparelho condicionador.

Como vemos a circulação do ar e os filtros se constituem nos elementos essenciais em todos os sistemas. Por isso, torna-se necessário conhecer seus tipos e propriedades.

\subsection{Sistema de Filtração para salas cirúrgicas}

Tela também é filtro. A que se coloca nas janelas, filtra moscas, mosquitos e outros insetos deixando entrar o ar fresco. $O$ filtro normal de espuma de poliuretano, filtra as partículas maiores da poeira e também deixa entrar ar fresco. Mas, quanto menor o tamanho das partículas, maior o problema de filtragem, e o tipo de filtros vai depender do trabalho de filtragem que queremos efetuar. $O$ número de fatores que devemos considerar para a escolha são sempre comuns. Podemos enumerá-los:

3.4.1. Eficiência - a eficiência será função do tipo e quantidade de partículas do ar. Existem testes padrão de comparação da eficiência de diversos filtros.

3.4.2. Capacidade de retenção - está ligada diretamente à quantidade de partículas captadas e define a freqüência com a qual se deve trocar determinado filtro, pois quanto maior a capacidade de retenção, maior a vida útil do filtro. Alguns engenheiros recomendam o uso de um pré-filtro para aumentar a capacidade de retenção.

3.4.3. Resistência ao fluxo de ar - o tamanho do filtro determinará o tamanho do ventilador necessário para impulsionar a quantidade de ar necessário por $\mathrm{m}^{2}$ do ambiente. 
3.4.4. Condições ambientais - deve ser resistente a qualquer condição que possa afetar o equipamento da filtragem como temperatura, umidade etc.

Existem 4 tipos de filtros:

3.4.4.1. de aderência

3.4.4.2. de retenção mecânica

3.4.4.3. eletrostáticos

3.4.4.4. de odores e gases.

O menos eficiente é o de aderência; os mais eficientes são os de retenção mecânica e os eletrostáticos têm aplicação especial e o seu custo de manutenção é dos mais elevados; os de odores e gases são usados onde a vida humana depende da remoção de gases tóxicos de ar, portanto, tem aplicação em máscaras contra gases respiradores dos submarinos atômicos, filtros de ar e cápsulas especiais.

\subsection{Fluxo laminar}

Depois do sistema de ar condicionado centralizado, sem recirculaçāo do ar e com adaptação dos filtros de alta eficiência, o fluxo laminar nos traz o ambiente ultra-estéril. principalmente para 0 Centro Cirúrgico e Unidade de Tratamento Intensivo.

O desenvolvimento do sistema foi feito pela Sandia Cor. (Companhia de Pesquisas e Desenvolvimentos) num esforço para reduzir-se o nível de contaminação por bactérias do ar em salas de operações.

Há dois tipos básicos para salas estéreis com fluxo laminar:

3.5.1. Fluxo horizontal - vai de uma parede para outra sendo a parede de entrada constituída de filtros HEPA e a saída do ar feita com pré-filtros;

3.5.2. Fluxo vertical - o teto é coberto com filtros HEPA, o ar passa por estes, indo de cima para baixo.

Em certas circunstâncias a instalação poderá ser feita dentro de um recinto já existente. O Wrightington Hospital na Suiça, fez a adaptação num conjunto de acrílico e uma série de experiências apontou completa ausência de bactérias no ar ambiente, diminuindo a porcentagem de infecções em cirurgias, ortopédicas de $7 \%$ a $0.5 \%$.

\section{$4-$ CONCULSÃO}

Nos EEUU, leis obrigam a regulamentação e o uso de componentes e sistemas adequados de condicionadores de ar. Entre nós, nem 
os requisitos mínimos são estudados e os condicionadores de janela continuam sendo instalados em salas cirúrgicas, jogando bactérias do ar nas feridas operatórias fazendo com que subsistam problemas de infecções pós-operatórias. Esta situação nos permite concluir que as autoridades representativas dos sistemas de saúde em nosso meio, ainda não tiveram oportunidade para apontar soluções de comprovada eficiência, como já ocorrem em outros países.

\section{RECOMENDAÇÕES}

Reforçando as recomendações do Dr. Aurélio Monteiro Filho, no seu artigo "Técnicas Modernas de Assepsia do Ar em Ambientes Hospitalares" sugerimos:

Nos Centros Cirúrgicos a serem constituídos:

5.1. Instalação do sistema de ar condicionado centralizado com a utilização das condições perfeitas de circulação e filtração do ar;

5.2. planejamento e construção em salas de operações do sistema de ar condicionado usando o "laminal Flow".

Nos Centros Cirúrgicos já existentes:

5.3.1. Substituição dos condicionadcres de janelas por sistemas centrais com condições recomendadas de circulação e filtração do ar;

5.4.2. instalação de filtros de alta eficiência nas grelhas de insuflação do ar quando existir um sistema central;

5.5.3. Utilização de unidades com "fluxo laminar", com fluxo horizontal ou vertical, de acordo com o espaço disponível para instalação de salas de operação ultra-estéreis. 